\title{
A comparison of infant and toddler feeding practices of mothers with and without histories of eating disorders
}

\author{
Elizabeth R. Hoffman*, Margaret E. Bentley*, Robert M. Hamer ${ }^{\dagger \ddagger}$, Eric A. Hodges ${ }^{\S}$, \\ Dianne S. Ward*T and Cynthia M. Bulik*t \\ *University of North Carolina at Chapel Hill, Gillings School of Global Public Health, Department of Nutrition, Chapel Hill, North Carolina, USA, \\ †University of North Carolina at Chapel Hill, Department of Psychiatry, Chapel Hill, North Carolina, USA, ‡University of North Carolina at Chapel Hill, \\ Gillings School of Global Public Health, Department of Biostatistics, Chapel Hill, North Carolina, USA, §University of North Carolina at Chapel Hill, School \\ of Nursing, Chapel Hill, North Carolina, USA, and "University of North Carolina at Chapel Hill, Center for Health Promotion and Disease Prevention, \\ Chapel Hill, North Carolina, USA
}

\begin{abstract}
This preliminary study surveyed the feeding practices of mothers with eating disorder histories through evaluation of mothers' reported feeding styles, child diet composition and restrictive special approaches to feeding. For this non-randomised cohort study, 25 mothers with eating disorder histories and 25 mothers with no history of an eating disorder with children ages 6-36 months were selected such that the groups were similar based on child age group and child sex. Mothers were compared on self-reported feeding style using the Infant Feeding Styles Questionnaire and on child diet composition and special feeding approaches using a modified version of the Toddler Diet Questionnaire from the Women, Infants, and Children program. Mothers with eating disorder histories scored lower on the restrictive feeding style subscale than controls. No significant differences were detected between groups in child diet including the percentage of mothers who breastfed, duration of breastfeeding, age at solid food introduction, daily number of meals or snacks or daily frequency of consumption of fruits, vegetables or protein foods. Mothers with eating disorder histories were more likely to report taking a restrictive special approach to feeding such as limiting processed foods or feeding organic foods only. Although mothers with eating disorder histories may not differ greatly from control mothers in terms of child diet composition (smaller effects may not have been detected due to limited sample size), they may be more likely to take restrictive special approaches to feeding which mirror dietary rules common in individuals with eating disorders.
\end{abstract}

Keywords: eating disorders, feeding behaviour, maternal behaviour, restrictive feeding, infant, toddler.

Correspondence: Dr Elizabeth R. Hoffman, Department of Psychiatry, University of North Carolina at Chapel Hill, CB \#7160, 101 Manning Drive, Chapel Hill, NC 27599-7160, USA. E-mail: elizabeth_hoffman@med.unc.edu

\section{Introduction}

An estimated $2.4 \%$ of women of childbearing age in the United States have met threshold DSM IV criteria for either anorexia nervosa (AN) or bulimia nervosa (BN) in their lifetime (Hudson et al. 2007). Fertility rates in women with current and past eating disorders appear to be similar to the general population, demonstrating that despite disordered eating behaviours and menstrual irregularities, many women with eating disorders become pregnant (Brinch et al. 1988; Bulik et al. 1999; Wentz et al. 2005). Compared with offspring of healthy women, the children of mothers with eating disorders tend to weigh less at birth and throughout the first few years of life and have greater risk of early feeding problems and nonorganic failure to thrive (Stein et al. 1996; Micali et al. 2009). In childhood, they exhibit greater dietary restraint and concern about shape and weight than children of healthy mothers (Woodside \& 
Shekter-Wolfson 1990; Stein et al. 2006). These observations suggest elevated risk for eating disorders among these children as they reach adolescence. Eating disorders are complex traits influenced by both genetic and environmental factors (Mazzeo et al. 2006). Although we are not yet to the point where we can identify genetic risk, one environmental factor that represents a potential critical avenue for early preventive intervention is the maternal-child feeding environment (Mazzeo et al. 2005).

Although most descriptive studies of mothers with eating disorders have included mothers currently meeting all criteria for eating disorder diagnoses, there is evidence that concerns over feeding, and difficulties during mealtimes persist for mothers even after clinical recovery from an eating disorder. Mothers with histories of eating disorders describe mealtimes as difficult due to expectations of eating together, fighting, mother's desire to skip the meal and stress over food preparation (Mazzeo et al.2005). These mothers also express concern about their children gaining weight or becoming overweight and reported desiring to restrict children's intake (Mazzeo et al. 2005). Studies using observational methods in mothers with a lifetime history of an eating disorder have found that mealtimes are marked with conflict (Stein et al. 1994) and decreased positive interactions (Waugh \& Bulik 1999) between mother and child. It is critical to better understand the challenges mothers with histories of eating disorders face in developing a healthy feeding environment for their children, as this group of clinically recovered individuals represents an even larger cross-section of the population than mothers currently meeting all criteria for eating disorders.
The current study surveyed the child-feeding practices of mothers with histories of eating disorders through the description of three main components of child feeding: feeding style, child diet and restrictive special approaches to feeding. Several studies have suggested that mothers with eating disorders may be more likely to exhibit a restrictive feeding style, characterised by close monitoring of child food consumption and overt limitation of types or quantities of foods offered (Honjo 1996; Agras et al. 1999; Duke et al. 2004; Mazzeo et al. 2005; Reba-Harrelson et al. 2010). Yet, these studies did not examine the actual composition of the diets of children of mothers with eating disorders. One study using a 3-day dietary recall reported no major differences in macro- or micronutrient consumption of 1-3-year-old children of mothers recovering from eating disorders compared with children of control mothers (Waugh \& Bulik 1999) but, again, did not evaluate for differences in specific types or quantities of specific foods consumed. Thus, while mothers with eating disorders may be more restrictive in feeding their young children, we do not understand specifically how this restriction manifests (e.g. Are mothers with eating disorders more likely to restrict the quantity or quality of foods offered?).The objective of this study was to evaluate feeding styles, child diet and restrictive special approaches used during feeding by mothers with histories of eating disorders and compare these feeding practices to those of mothers with no such history. We hypothesised that mothers with histories of eating disorders would have higher scores for restrictive feeding style, and that this would be manifested as more dietary rules for their children (regarding both food quality and quantity) including

\section{Key messages}

- Children of mothers with eating disorders are at increased risk of childhood feeding problems and disordered eating later in life.

- Mothers with histories of eating disorders report less restrictive feeding styles than mothers with no history. No differences were found in child diet composition.

- Mothers with histories of eating disorders may be more likely to employ restrictive special approaches to feeding such as feeding no processed foods or organic foods only.

- More study is needed to determine if this increased monitoring of child diet quality results in positive health outcomes for children or increases risk for disordered eating later in life. 
longer duration of breastfeeding, no fruit juice, no sweets, fewer daily snacks, lower frequency of consumption of proteins, but not fruits and vegetables, children being less likely to eat what the family eats and, finally, more restrictive special approaches to feeding such as low processed, no added sugar or organic foods only.

\section{Material and methods}

\section{Participants}

Women with a history of an eating disorder with children between the ages of 6 and 36 months were recruited from the community through emails and fliers distributed to university students and staff, mother's clubs and local daycare centres. Thirty-three women were screened and interviewed using the Structured Clinical Interview for DSM-IV Axis I Disorders-Patient Edition (SCID-I/P)(First et al. 2002), and 25 women met inclusion criteria for previous history of either $\mathrm{AN}, \mathrm{BN}$ or eating disorder not otherwise specified (EDNOS). Women with a history of only binge eating disorder (BED) or a body mass index (BMI) greater than $30 \mathrm{~kg} \mathrm{~m}^{-2}$ were not included in this study, as the literature on child feeding in both of these groups suggests that they may behave differently than mothers with $\mathrm{AN}, \mathrm{BN}$ or EDNOS due to a greater focus on childhood overweight and less concern over modelling unhealthy body shape and weight attitudes towards their children (Birch \& Fisher 2000; Faith et al. 2004; Reba-Harrelson et al. 2010). Participants must not have met threshold criteria for AN, BN or EDNOS in the past 28 days and must have maintained a BMI of at least $18.5 \mathrm{~kg} \mathrm{~m}^{-2}$ for the 3 months prior to participation.

Twenty-five control women with children between the ages of 6 and 36 months who had never experienced an eating disorder were recruited similarly from the community. Eligible mothers who had not met lifetime DSM-IV criteria for AN, BN, BED or EDNOS according to the SCID-I/P and who had a BMI between 18.5 and $30 \mathrm{~kg} \mathrm{~m}^{-2}$ were recruited based on child age group (within 6-month age bands) and child sex. Although participants were not individually matched in a pairwise way, they were recruited in such a way that the mothers with histories of eating disorders and control mothers had the same proportion of child age groups and child sexes.

Exclusion criteria for both mothers with histories of eating disorders and control mothers were psychosis, including schizophrenia, bipolar I disorder, current significant suicidal ideation, alcohol or drug dependence in the past year and any social service inquiries regarding child neglect. No women were excluded based on these criteria.

All mothers were screened by phone, and eligible participants were then visited in their homes where a clinical interview was conducted to determine relevant Axis I diagnoses. If mothers were still eligible after interview, they were given a packet of questionnaires that they were instructed to complete over the following week and return to the study coordinator in the mail. There was a $100 \%$ completion rate from eligible participants.

Mothers received a $\$ 20$ gift certificate for their participation in this study. Ethical approval for this study was granted by the Biomedical Institutional Review Board of The University of North Carolina at Chapel Hill, and all participants provided informed consent.

\section{Clinician-administered assessments}

The SCID-I/P

The SCID-I/P [Modules A (Mood), B/C (Psychotic Screen), E (Substance Use Disorders) and H (Eating Disorders)] (First et al.2002) was used to assess eating disorder history and comorbid Axis I disorders (alcohol or drug dependence and psychosis including schizophrenia and bipolar I disorder). The SCID-I/P is a semi-structured interview which was conducted by a clinical interviewer trained to criterion.

\section{Anthropometric data}

Participants' weight was assessed using a digital scale (Tanita HD-351 Digital Weight Scale; Tanita Corporation of America Inc., Arlington Heights, IL, USA); scales were calibrated regularly according to protocol. A stadiometer was used to assess all participants' height. BMI was then calculated as weight $(\mathrm{kg})$ (height $)^{-2}$. Children were weighed wearing only 
Table I. Sample items from the infant feeding style questionnaire

\begin{tabular}{|c|c|c|}
\hline Feeding style & No. items & Sample items \\
\hline Laissez-Faire & 11 & $\begin{array}{l}\text { A toddler should be able to eat whatever s/he wants for snacks } \\
\text { I watch TV while feeding (child) } \\
\text { I keep track of how much food (child) eats* }\end{array}$ \\
\hline Pressuring & 17 & $\begin{array}{l}\text { I try to get (child) to eat even if not hungry } \\
\text { It is important for a toddler to finish all the food on his/her plate } \\
\text { When (child) cries, I immediately feed him/her }\end{array}$ \\
\hline Restrictive & 11 & $\begin{array}{l}\text { I carefully control how much (child) eats } \\
\text { A toddler should never eat sugary food like cookies } \\
\text { A toddler should only eat healthy food }\end{array}$ \\
\hline Indulgent & 32 & $\begin{array}{l}\text { I allow (child) to eat desserts/sweets if s/he wants } \\
\text { Toddlers should be allowed to watch TV while eating to keep them from crying } \\
\text { I allow (child) to eat fast food to keep him/her happy }\end{array}$ \\
\hline Responsive & 12 & $\begin{array}{l}\text { I let (child) decide how much to eat } \\
\text { (Child) knows when s/he is full } \\
\text { It is important to help or encourage a toddler to eat }\end{array}$ \\
\hline
\end{tabular}

*Item reverse scored.

a clean diaper using a digital scale (Tanita BD-585 Digital Baby Scale; Tanita Corporation of America Inc.). Child length was measured three times in the recumbent position using a calibrated length board (O'Leary Length Board) by two trained research staff, and the average of the three measurements was recorded. Child weight and length was then converted into age- and sex-specific z-scores per the revised growth charts from the Centers for Disease Control and Prevention (Kuczmarski et al. 2000).

\section{Self-report assessments}

Infant Feeding Style Questionnaire (IFSQ) (Thompson et al. 2009)

The IFSQ is a self-report measure of parents' beliefs about how to best feed their child and what parental behaviours they exhibit when feeding their child. Subscale scores are calculated as means of the response items (coded on a 5-point scale) for each of five major feeding styles: (1) laissez-faire, which describes parents who place few limits on quantity or quality of food and take an overall 'hands-off' approach to feeding; (2) pressuring, which describes parents who pressure their children to eat more food and use foods to comfort their children; (3) restrictive, which describes parents who place overt limitations on quantity and/or quality of foods consumed; (4) indul- gent, which describes parents who place no limits on quantity or quality of foods consumed, while also being highly involved with feeding; and (5) responsive, which describes parents who pay close attention to their children's hunger and satiety cues and monitor the quality of their diet. Sample items from each of the five major feeding style subscales are given in Table 1. A complete description of all items loading onto each feeding style has been published previously (Thompson et al. 2009). Categorical confirmatory factor analysis has been used to validate that items hypothesised a priori as measures of each of the five major feeding styles yielded well-fitting models in two independent samples of low-income AfricanAmerican mothers of infants and young children (Thompson et al. 2009).

\section{Toddler Diet Questionnaire}

The Toddler Diet Questionnaire is a semiquantitative food frequency questionnaire adapted from the Infant and Toddler Diet Questionnaire used to assess dietary/feeding practices of mothers in the Women, Infant and Children federal nutrition program in the United States (Toddler Diet Questionnaire 2007). The questionnaire assesses frequency and type of consumption of proteins, fruits and vegetables, milk, juice, sweets and snack items. 
Breastfeeding status, breastfeeding duration and timing of introduction of complementary foods are also assessed. Lastly, the questionnaire was adapted to include a 'special approaches' section, which asked mothers if they followed any special approaches when feeding their children. Options for special approaches included low/no processed foods, organic foods only, no sugar added, gluten free, lactose free, low/no carbohydrate and low/no fat.

\section{Eating Disorder Examination Questionnaire (EDE-Q)} (Fairburn \& Beglin 1994)

The EDE-Q is well-studied and frequently used 36-item self-report questionnaire modelled after the Eating Disorder Examination semi-structured interview (Fairburn \& Cooper 1993) designed to assess eating disorder symptoms over the previous 28 days. The questionnaire yields four subscale scores (Dietary Restraint, Eating Concern, Shape Concern and Weight Concern) as well as a global score that is the average of the four subscales. Mean EDE-Q global score for individuals with eating disorders in a community sample was 3.09 , while mean global score was 1.30 in individuals without eating disorders (Mond et al. 2004). The subscales have high internal consistency $(\alpha=0.78-0.93)$ and 2-week test-retest reliability (Pearson $r=0.81-0.94$; Luce \& Crowther 1999).

\section{Beck Depression Inventory-II (BDI-II) (Beck et al. 1996)}

The BDI-II is a 21-item self-report questionnaire that was used to assess the severity of current depressive symptoms; the revised version extends the reporting time frame to 2 weeks and has good internal consistency in post-partum mothers $(\alpha=0.94)$ (Britton 2011) and 1-week test-retest reliability $(r=0.93)$ (Beck et al. 1996). Mean BDI-II score was 8.47 in a community sample of mothers 1 month post-partum (Britton 2011), 5.2-6.4 in individuals recovered from eating disorders and 1.1 in a non-eating disorder community sample (Wagner et al. 2006).

Beck Anxiety Inventory (BAI) (Beck et al. 1988)

The BAI is a 21-item self-report questionnaire that was used to assess current anxiety. The BAI focuses on somatic symptoms of anxiety over the past week. Convergence with other measures of anxiety has been demonstrated; the BAI has high internal consistency $(\alpha=0.92)$ and test-retest reliability over 1 week $(r=0.75)$ in a sample of psychiatric outpatients (Beck et al. 1988). Current depressive and anxiety symptoms were measured in order to better describe underlying psychopathology in our sample that could influence maternal feeding practices (Hurley et al. 2008).

\section{Statistical analyses}

All analyses were conducted with Statistical Analysis Software (SAS) version 9.2 (SAS Institute Inc., Cary, NC, USA). Means and standard deviations are presented for all continuous variables and percent distribution for categorical variables. Student's $t$-tests were used to evaluate differences between groups for continuous variables. Fisher's exact test was used to evaluate differences between groups for categorical variables. Standardised effect sizes were calculated as relative risk (RR) for binary categorical variables and gamma values for categorical variables with greater than two categories. Ninety-five per cent confidence intervals for the differences in means were calculated for continuous variables. There were missing data for several demographic variables for one participant due to her choice not to disclose information about current weight or level of education. Data were also considered missing for subscale scores of the IFSQ when a participant responded 'not applicable' to more than one response item loading on to a particular subscale. If a participant responded 'not applicable' to only one item for a subscale of the IFSQ, the mean subscale score was calculated without that item. All significance tests were two-tailed, and a $P$-value of $<0.05$ was considered significant. A sample size of 25 participants per group was chosen for this preliminary study in order to have $80 \%$ power at $\alpha=0.05$ (twotailed) to detect an effect size of 0.8 between groups, an effect size considered large [SAS $® ;$ (Cohen 1992)]. Because this was a preliminary study, it was not reasonable to expect that the study would have power to detect medium or small effect sizes. This study supplies proof of concept and preliminary data that can 
be used to justify further larger studies. Given that this was a small study that was hypothesis driven but also intended to generate hypotheses for future larger studies and statistical power was low, no correction was made for multiple testing.

\section{Results}

\section{Maternal characteristics}

The sample comprised 50 mothers of children ages 6-36 months ( 25 with a history of an eating disorder and 25 controls). Of the 25 women with a history of an eating disorder, 13 had a history of AN (nine restricting type and four binge-purge type), 13 had a history of $\mathrm{BN}$ (six non-purging type and seven purging type), two had a history of BED (in addition to another past eating disorder diagnosis) and two had a history of EDNOS (both met all criteria for AN except their lowest BMI was $>18.5 \mathrm{~kg} \mathrm{~m}^{-2}$ ). Three women had a history of two different eating disorder diagnoses (AN and BN, AN and BED, BN and EDNOS), and one woman had a history of three different eating disorder diagnoses (AN, BN and BED).

Mothers with histories of eating disorders were significantly older (32.72 years \pm 4.61$)$ than control mothers $\quad[29.68$ years \pm 1.99 ; Student's $t$-test: $t(48)=3.02, P<0.01]$. The two groups did not differ significantly in their level of education, race or parity. The majority of mothers in both groups was white and had at least a college degree. The groups did not differ significantly on mothers' current BMI or highest nonpregnant adult BMI, but mothers with histories of eating disorders reported a significantly lower lifetime BMI (18.22 $\left.\mathrm{kg} \mathrm{m}^{-2} \pm 1.90\right)$ than control mothers $\left[20.34 \mathrm{~kg} \mathrm{~m}^{-2} \pm 2.31\right.$; Student's $t$-test: $t(48)=-3.55$, $P<0.01]$. Mothers with histories of eating disorders also had significantly higher scores on current eating disorder symptoms on the EDE-Q compared with control mothers, but scores in both groups were lower than published scores of individuals with current eating disorders (Mond et al. 2004). The groups did not differ significantly on reported symptoms of depression measured with the BDI-II, although there was a trend towards higher scores for current depressive symptoms for mothers with histories of eating disorders. Of note, the mean BDI-II score for mothers with histories of eating disorders was $5.68 \pm 5.46$, which is similar to scores seen in another study of women recovering from eating disorders (Wagner et al.2006) and is still within the lowest score range of 0-13 thought to correlate with minimal clinical depression (Beck et al. 1996). Mothers with histories of eating disorders reported greater anxiety in the past week on the BAI $(4.56 \pm 3.80)$ than control mothers [2.58 \pm 1.80 ; Student's $t$-test: $t(48)=2.95$, $P<0.01]$; however, this does not represent a clinically significant difference as the mean score of 4.56 is still within the lowest BAI score range of 0-7 representing a minimal level of anxiety (Beck et al. 1988). Characteristics of participating mothers are found in Table 2.

\section{Child characteristics}

Control mothers were matched to mothers with histories of eating disorders based on child age group and child sex. There was no significant difference between groups in child birthweight or child's current weight-for-length z-score (see Table 3 ).

\section{Feeding style}

The groups did not differ significantly on scores of laissez-faire, pressuring, indulgent or responsive feeding styles. Mothers with histories of eating disorders scored significantly lower on the restrictive feeding style subscale than control mothers [2.71 \pm 0.46 and $2.99 \pm 0.46$, respectively; Student's $t$-test: $t(47)=-2.18, P=0.04]$ and there was a trend towards higher scores on the indulgent feeding style subscale for mothers with histories of eating disorders. Both groups scored highest on responsive feeding out of the five feeding style subscales. Overall, IFSQ subscale scores in this sample were similar to those reported in the Infant Care cohort of 154 lowincome African-American mothers in North Carolina used to develop the questionnaire. The infant care cohort also had highest scores for the responsive feeding style subscale $(4.07 \pm 0.58)$ with lower scores for restrictive (3.62 \pm 0.68$)$, pressuring $(2.32 \pm 0.63)$, laissez-faire $(1.78 \pm 0.52)$ and indulgent $(1.67 \pm 0.60)$ 
Table 2. Demographic and clinical characteristics of mothers

\begin{tabular}{|c|c|c|c|c|c|c|c|}
\hline & \multicolumn{2}{|c|}{$\begin{array}{l}\text { Mothers with histories } \\
\text { of eating disorders }\end{array}$} & \multicolumn{2}{|c|}{$\begin{array}{l}\text { Control } \\
\text { mothers }\end{array}$} & \multirow[t]{2}{*}{ Test statistic } & \multirow[t]{2}{*}{$P$-value } & \multirow[t]{2}{*}{$\begin{array}{l}95 \% \mathrm{CI} \\
\text { difference }\end{array}$} \\
\hline & Mean & SD & Mean & SD & & & \\
\hline Age (year) & 32.72 & 4.61 & 29.68 & 1.99 & $t(48)=3.02$ & $P<0.01$ & $(1.02,5.06)$ \\
\hline Current BMI $\left(\mathrm{kg} \mathrm{m}^{-2}\right)$ & 22.37 & 2.69 & 23.04 & 3.04 & $t(47)=-0.82$ & $P=0.42$ & $(-2.32,0.98)$ \\
\hline Lowest adult BMI $\left(\mathrm{kg} \mathrm{m}^{-2}\right)$ & 18.22 & 1.90 & 20.34 & 2.31 & $t(48)=-3.55$ & $P<0.01$ & $(-3.33,-0.92)$ \\
\hline \multirow[t]{2}{*}{ Highest adult BMI $\left(\mathrm{kg} \mathrm{m}^{-2}\right)$} & 24.25 & 3.46 & 24.08 & 2.98 & $t(48)=0.18$ & $P=0.86$ & $(-1.67,2.00)$ \\
\hline & No. & $\%$ & No. & $\%$ & & & \\
\hline Parity & & & & & FET & $P=0.99$ & \\
\hline 1 child & 18 & 72 & 19 & 76 & & & \\
\hline$>1$ child & 7 & 28 & 6 & 24 & & & \\
\hline Education & & & & & FET & $P=0.32$ & \\
\hline GED or high school & 1 & 4 & 0 & 0 & & & \\
\hline Some college & 0 & 0 & 3 & 12 & & & \\
\hline College graduate & 7 & 29 & 8 & 32 & & & \\
\hline Post-graduate degree & 16 & 67 & 14 & 56 & & & \\
\hline Race & & & & & FET & $P=0.99$ & \\
\hline White & 24 & 96 & 24 & 96 & & & \\
\hline \multirow[t]{2}{*}{ Other } & 1 & 4 & 1 & 4 & & & \\
\hline & Mean & SD & Mean & $\mathrm{SD}$ & & & \\
\hline \multicolumn{8}{|l|}{ EDE-Q } \\
\hline Global & 1.71 & 1.40 & 0.91 & 0.83 & $t(48)=2.46$ & $P=0.02$ & $(0.14,1.45)$ \\
\hline Restraint & 1.28 & 1.40 & 1.17 & 1.25 & $t(48)=0.30$ & $P=0.77$ & $(-0.64,0.87)$ \\
\hline Eating concern & 1.14 & 1.25 & 0.20 & 0.22 & $t(48)=3.73$ & $P<0.01$ & $(0.43,1.45)$ \\
\hline Shape concern & 2.23 & 1.92 & 1.20 & 1.16 & $t(48)=2.30$ & $P=0.03$ & $(0.13,1.94)$ \\
\hline Weight concern & 1.86 & 1.60 & 0.90 & 0.97 & $t(48)=2.59$ & $P=0.02$ & $(0.21,1.72)$ \\
\hline BDI-II & 5.68 & 5.46 & 4.32 & 4.69 & $t(48)=0.94$ & $P=0.35$ & $(-1.53,4.25)$ \\
\hline BAI & 4.56 & 3.80 & 2.58 & 1.80 & $t(48)=2.95$ & $P<0.01$ & $(0.79,4.17)$ \\
\hline
\end{tabular}

SD, standard deviation; 95\% CI, 95\% confidence interval for the difference in means; FET, Fisher's exact test; EDE-Q, Eating Disorders Examination Questionnaire; BDI, Beck Depression Inventory; BAI, Beck Anxiety Inventory.

Table 3. Demographic and clinical characteristics of children

\begin{tabular}{|c|c|c|c|c|c|c|c|}
\hline & \multirow{2}{*}{\multicolumn{2}{|c|}{$\begin{array}{l}\text { Children of mothers } \\
\text { with histories of } \\
\text { eating disorders }\end{array}$}} & \multicolumn{2}{|c|}{$\begin{array}{l}\text { Children of } \\
\text { control mothers }\end{array}$} & \multirow[t]{3}{*}{ Test statistic } & \multirow[t]{3}{*}{$P$-value } & \multirow[t]{3}{*}{$\begin{array}{l}95 \% \mathrm{CI} \\
\text { difference }\end{array}$} \\
\hline & & & \multirow{2}{*}{ No. } & \multirow{2}{*}{$\%$} & & & \\
\hline & No. & $\%$ & & & & & \\
\hline \multicolumn{8}{|l|}{ Child sex } \\
\hline Male & 13 & 52 & 13 & 52 & & & \\
\hline \multicolumn{8}{|l|}{ Age group } \\
\hline 6-12 months & 8 & 32 & 8 & 32 & & & \\
\hline $13-18$ months & 5 & 20 & 5 & 20 & & & \\
\hline 19-24 months & 4 & 16 & 4 & 16 & & & \\
\hline 25-30 months & 3 & 12 & 3 & 12 & & & \\
\hline \multirow[t]{2}{*}{$31-36$ months } & 5 & 20 & 5 & 20 & & & \\
\hline & Mean & SD & Mean & SD & & & \\
\hline Age (mo) & 18.92 & 9.76 & 19.56 & 9.35 & $t(48)=-0.24$ & $P=0.81$ & $(-6.08,4.80)$ \\
\hline Birthweight (g) & 3434.8 & 438.5 & 3347.5 & 370.6 & $t(48)=0.76$ & $P=0.45$ & $(-143.5,318.2)$ \\
\hline Current weight-for-length z-score & 0.16 & 0.60 & 0.15 & 1.01 & $t(47)=0.03$ & $P=0.98$ & $(-0.48,0.49)$ \\
\hline
\end{tabular}

$95 \%$ CI, $95 \%$ confidence interval for the difference in means. 
Table 4. Feeding style scale scores from the infant feeding style questionnaire

\begin{tabular}{|c|c|c|c|c|c|c|c|}
\hline \multirow[t]{2}{*}{ Feeding style } & \multicolumn{2}{|c|}{$\begin{array}{l}\text { Mothers with histories } \\
\text { of eating disorders }\end{array}$} & \multicolumn{2}{|c|}{$\begin{array}{l}\text { Control } \\
\text { mothers }\end{array}$} & \multirow[t]{2}{*}{ Test statistic } & \multirow[t]{2}{*}{$P$-value } & \multirow{2}{*}{$\begin{array}{l}95 \% \text { CI } \\
\text { difference } \\
\text { in means }\end{array}$} \\
\hline & Mean & SD & Mean & $\mathrm{SD}$ & & & \\
\hline Laissez-Faire & 1.84 & 0.36 & 1.89 & 0.50 & $t(43)=-0.40$ & $P=0.69$ & $(-0.32,0.21)$ \\
\hline Pressuring & 1.78 & 0.57 & 1.85 & 0.31 & $t(45)=-0.52$ & $P=0.61$ & $(-0.34,0.20)$ \\
\hline Restrictive & 2.71 & 0.46 & 2.99 & 0.46 & $t(47)=-2.18$ & $P=0.04$ & $(-0.55,-0.02)$ \\
\hline Indulgent & 1.27 & 0.26 & 1.18 & 0.17 & $t(46)=1.35$ & $P=0.19$ & $(-0.04,0.22)$ \\
\hline Responsive & 4.02 & 0.33 & 4.11 & 0.43 & $t(46)=-0.74$ & $P=0.47$ & $(-0.31,0.14)$ \\
\hline
\end{tabular}

Table 5. Child diet composition from the toddler diet questionnaire

\begin{tabular}{|c|c|c|c|c|c|c|c|}
\hline \multirow[t]{3}{*}{ Variable } & \multirow{2}{*}{\multicolumn{2}{|c|}{$\begin{array}{l}\text { Mothers with } \\
\text { histories of } \\
\text { eating disorders }\end{array}$}} & \multicolumn{2}{|c|}{$\begin{array}{l}\text { Control } \\
\text { mothers }\end{array}$} & \multirow[t]{3}{*}{ Test statistic } & \multirow[t]{3}{*}{$P$-value } & \multirow[t]{3}{*}{ Effect size } \\
\hline & & & \multirow{2}{*}{ No. } & \multirow{2}{*}{$\%$} & & & \\
\hline & No. & $\%$ & & & & & \\
\hline Breastfed $>1$ month & 24 & 96 & 24 & 96 & FET & $P=0.99$ & $1.00(0.24-4.11)^{*}$ \\
\hline Currently breastfeeding & 13 & 52 & 9 & 36 & FET & $P=0.39$ & $1.38(0.79-2.39)^{*}$ \\
\hline Age at solid food introduction: & & & & & FET & $P=0.19$ & $0.54(0.34-0.88)^{*}$ \\
\hline 4-6 months & 20 & 80 & 24 & 96 & & & \\
\hline After 7 months & 5 & 20 & 1 & 4 & & & \\
\hline No sweets & 7 & 28 & 6 & 24 & FET & $P=0.99$ & $1.11(0.61-2.02)^{*}$ \\
\hline No juice & 16 & 64 & 14 & 56 & FET & $P=0.77$ & $1.18(0.66-2.14)^{*}$ \\
\hline Child eats what family eats: & & & & & FET & $P=0.11$ & $0.43^{\dagger}$ \\
\hline Most of the time & 12 & 48 & 17 & 68 & & & \\
\hline Sometimes & 5 & 20 & 6 & 24 & & & \\
\hline \multirow[t]{2}{*}{ Rarely } & 8 & 32 & 2 & 8 & & & \\
\hline & Mean & SD & Mean & $\mathrm{SD}$ & & & \\
\hline $\begin{array}{l}\text { Duration of breastfeeding (if no longer } \\
\text { breastfeeding; in mo.) }\end{array}$ & 11.92 & 5.69 & 12.87 & 5.72 & $t(25)=-0.43$ & $P=0.67$ & $(-5.50,3.60)^{\ddagger}$ \\
\hline No. meals per day & 3.00 & 0.58 & 3.28 & 0.61 & $t(48)=-1.66$ & $P=0.10$ & $(-0.62,0.06)^{\ddagger}$ \\
\hline No. snacks per day & 1.76 & 0.97 & 2.00 & 0.76 & $t(48)=-0.97$ & $P=0.34$ & $(-0.74,0.26)^{\ddagger}$ \\
\hline Protein consumed (times per day) & 2.73 & 0.93 & 2.42 & 0.65 & $t(44)=1.31$ & $P=0.19$ & $(-0.17,0.79)^{\ddagger}$ \\
\hline Fruits and vegetables consumed (times per day) & 3.00 & 1.10 & 3.36 & 0.99 & $t(47)=-1.20$ & $P=0.24$ & $(-0.96,0.24)^{\ddagger}$ \\
\hline
\end{tabular}

FET, Fisher’s exact test. *Relative risk (95\% confidence interval). ${ }^{\dagger}$ Gamma-value. ${ }^{\ddagger} 95 \%$ confidence interval for difference of means.

feeding style subscales (presented in order of decreasing mean subscale scores; Thompson et al. 2009). Feeding style scale scores from the IFSQ are presented in Table 4.

In a post hoc analysis to ensure our observations were not strongly related to maternal age, we evaluated the association between maternal age and subscale score for restrictive feeding. There was a small negative correlation between maternal age and restrictive feeding (Pearson's correlation: $r=-0.11$ ) that was not statistically significant $(P=0.46)$.

\section{Child diet composition}

Components of child diet measured with the Toddler Diet Questionnaire are presented in Table 5. Mothers with histories of eating disorders did not differ significantly from control mothers in percentage breastfeeding longer than 1 month, percentage currently breastfeeding or overall duration of breastfeeding (for those mothers in each group who had stopped breastfeeding; 12 mothers with histories of eating disorders and 15 control mothers; see Table 5). Mean 
Table 6. Restrictive special approaches to feeding reported by mothers

\begin{tabular}{|c|c|c|c|c|c|c|c|}
\hline \multirow[t]{3}{*}{ Variable } & \multirow[t]{3}{*}{ Category } & \multirow{2}{*}{\multicolumn{2}{|c|}{$\begin{array}{l}\text { Mothers with } \\
\text { histories of } \\
\text { eating disorders } \\
(n=25)\end{array}$}} & \multicolumn{2}{|c|}{$\begin{array}{l}\text { Control } \\
\text { mothers } \\
(n=25)\end{array}$} & \multirow[t]{3}{*}{$\begin{array}{l}\text { FET } \\
P \text {-value }\end{array}$} & \multirow[t]{3}{*}{$\begin{array}{l}\text { Relative } \\
\text { risk }(95 \% \mathrm{CI})\end{array}$} \\
\hline & & & & \multirow{2}{*}{ No. } & \multirow[t]{2}{*}{$\%$} & & \\
\hline & & No. & $\%$ & & & & \\
\hline Any special approach & & 22 & 88 & 15 & 60 & 0.05 & $2.58(0.92-7.20)$ \\
\hline \multirow[t]{9}{*}{ Specific special approach } & Low processed & 15 & 60 & 9 & 36 & 0.16 & $1.62(0.92-2.89)$ \\
\hline & Organic only & 8 & 32 & 5 & 20 & 0.52 & $1.34(0.77-2.33)$ \\
\hline & No added sugar & 9 & 36 & 8 & 32 & 0.99 & $1.09(0.62-1.93)$ \\
\hline & No animal products & 1 & 4 & 1 & 4 & 0.99 & $1.00(0.24-4.11)$ \\
\hline & Gluten free & 0 & 0 & 1 & 4 & 0.99 & - \\
\hline & Lactose free & 0 & 0 & 0 & 0 & - & - \\
\hline & Low fat & 0 & 0 & 1 & 4 & 0.99 & - \\
\hline & Low carbohydrate & 0 & 0 & 0 & 0 & - & - \\
\hline & Other & 6 & 24 & 6 & 24 & 0.99 & $1.00(0.52-1.91)$ \\
\hline
\end{tabular}

FET, Fisher's exact test.

duration of breastfeeding for both groups was about 1 year $(11.92 \pm 5.69$ months for mothers with histories of eating disorder and $12.87 \pm 5.72$ months for controls). All but one mother in each group breastfed for at least 1 month. Groups did not differ significantly in child age at introduction of solid foods, although there was a trend towards more children of mothers with histories of eating disorders being introduced to solid foods after 7 months $(n=5$ children of mothers with eating disorder histories and $n=1$ child of a control mother). The majority ( $n=20$ children of mothers with histories of eating disorders and $n=24$ children of control mothers) of children in both groups were introduced to solid food between 4 and 6 months of age. Additionally, there was a trend towards more mothers with histories of eating disorders reporting that their child 'rarely' eats what the family eats $(n=8$ mothers with histories of eating disorders and $n=2$ control mothers) with more control mothers reporting that their child eats what the family eats 'most of the time' ( $n=12$ mothers with histories of eating disorders and $n=17$ control mothers; FET $P=0.11$ ).

No significant difference was detected between groups for number of meals or snacks per day, daily frequency of consumption of fruit and vegetables or daily frequency of consumption of protein foods. Groups were also similar in percentage of mothers who reported that their child never drank juice (64\% mothers with histories of eating disorders and $56 \%$ control mothers) or never ate sweets (28\% mothers with histories of eating disorders and $24 \%$ control mothers; see Table 5).

\section{Restrictive special approaches to feeding}

When asked if they took any special approaches to feeding their child, mothers with histories of eating disorders were more likely to report a special approach to feeding than control mothers [88\% mothers with histories of eating disorders and $60 \%$ control mothers; Fisher's exact test $P=0.05$, RR(95\% CI $=2.58(0.92-7.20)$; see Table 6]. The most commonly reported special approach in both groups was limiting the amount of processed food (60\% mothers with histories of eating disorders and 36\% control mothers). Groups did not differ significantly in the percentage of mothers who reported feeding foods that were organic only, with no added sugar, gluten free, lactose free, low fat, low carbohydrate or foods containing no animal products. Mothers were also able to note other special approaches that were not included as options on the questionnaire. Other special approaches reported included no fast food (one mother with eating disorder and one control mother), nitrate-free hot dogs (one mother with eating disorder), no beef (two mothers with eating 
disorders), hormone-free and grain-fed meats only (one mother with eating disorder and one control mother), no high-fructose corn syrup (one mother with eating disorder and one control mother), homemade foods only (two control mothers) and simple foods only (one control mother).

\section{Discussion}

Some significant differences were detected in feeding practices between mothers with histories of eating disorders and control mothers including lower scores for restrictive feeding style yet higher prevalence of restrictive special approaches to feeding in mothers with histories of eating disorders. No significant differences were detected on measures of child diet composition, such as food frequency measures and prevalence and duration of breastfeeding, although the small sample size of this preliminary study limited our ability to detect small or medium effect sizes. There were trends towards more children of mothers with histories of eating disorders being introduced to solid food after 7 months compared with children of controls and more mothers with histories of eating disorders reporting that their child 'rarely' eats what the family eats. Yet, most children in both groups were introduced to solid foods at 4-6 months of age, the time period recommended by the American Academy of Pediatrics (Gartner et al. 2005).

In terms of feeding styles, both mothers with histories of eating disorders and control mothers scored highest on the responsive feeding subscale out of all subscales of the IFSQ, a finding similar to that in the Infant Care cohort of low-income African-American mothers used to develop the questionnaire (Thompson et al. 2009). Contrary to our hypothesis, the only difference between groups in feeding style scores was that mothers with histories of eating disorders had a lower mean score for restrictive feeding than control mothers and a trend towards a higher mean score for indulgent feeding. Despite this difference, scores were low for the restrictive feeding style subscale in both groups relative to the Infant Care cohort published previously (Thompson et al. 2009). Previous literature has suggested that breastfeeding may help to protect mothers against restrictive and pressuring feeding practices and promote more responsive feeding (Fisher et al. 2000; Taveras et al. 2004; Blissett \& Farrow 2007), as breastfeeding eliminates the option of feeding a set quantity of food and allows parents to become more sensitive to infant hunger and satiety cues. In our sample, all but one mother in each group breastfed for greater than 1 month, and the mean duration of breastfeeding for mothers who had weaned their children was around 12 months. Thus, the high prevalence and long duration of breastfeeding in our sample may explain the high scores in responsive feeding and relatively low scores in restrictive and pressuring feeding styles in both groups.

The lower mean score for the restrictive feeding style subscale in mothers with histories of eating disorders compared to controls has not been reported in previous studies. Eating disorder history has been positively associated with restrictive feeding practices at 7 years of age (Duke et al. 2004) but not at 1 year (Farrow \& Blissett 2005). Additionally, anxiety during the postnatal period predicts restrictive feeding at 1 year (Farrow \& Blissett 2005). In our sample, mothers with histories of eating disorders had higher scores on both disordered eating and anxiety symptoms than controls, yet they scored lower on the restrictive feeding subscale. Our sample of mothers with histories of eating disorders included a majority of women with histories of AN-like presentations (AN or EDNOS characterised by subthreshold AN; 15 out of the 25 mothers with eating disorders had a history of either AN or EDNOS). This sample composition could explain the lower levels of restrictive feeding reported; a population-based study of feeding styles in mothers with eating disorders found that mothers with $\mathrm{BN}$ and $\mathrm{BED}$ reported higher levels of restrictive feeding than mothers with no eating disorder, but mothers with AN actually reported lower levels of restrictive feeding similar to our finding (RebaHarrelson et al. 2010). Lastly, several studies have found that maternal age is negatively associated with restrictive feeding (Taveras et al. 2004; Blissett \& Farrow 2007), and mothers with histories of eating disorders were significantly older than control mothers in our sample. Our post hoc analysis did not detect a significant association between maternal age 
and restrictive feeding rendering it unlikely that age alone is responsible for the observed difference between groups.

Mothers with histories of eating disorders were more likely to report taking some special approach to feeding their child. The most common special approach reported was limiting processed foods. This finding is particularly interesting given that women with histories of eating disorders may be more likely to be concerned with eating only 'healthy' foods in their own diet (Dellava et al. 2011) or following specific dietary rules meant to influence their shape or weight (Cooper \& Fairburn 1987; Bardone-Cone et al. 2010). The nature of the questionnaire used did not allow us to determine whether the special approaches taken reflected rigid feeding rules or more flexible guidelines focused on healthy eating. It will be critical for future investigations to determine whether these special approaches are implemented covertly (e.g. the child is only given low processed foods in the home but is not aware of any explicit rules against eating processed foods) or overtly (e.g. the child is aware that he/she must not eat processed foods). The overt implementation of a special feeding approach would be consistent with a restrictive feeding style. Typically, however, these types of feeding behaviours (limiting processed foods, feeding organic or natural foods only) are not captured in questionnaires assessing feeding style (Birch et al. 2001; Thompson et al. 2009). Whether these special approaches could prove beneficial or harmful for children in later life is unknown, but past research has shown that overt restrictive feeding at a young age can lead to dysregulated eating later in life (Fisher \& Birch 2002).

Although novel and informative for future investigations, our study nonetheless has limitations that should be considered when interpreting the results. First, as this was a preliminary study and the sample size was relatively small, we lacked power to detect small or medium effect sizes. Thus, all instances of failure to find a significant effect should not be taken to imply that there was no effect. Although we did explore possible confounding factors such as maternal age, our small sample size limited our ability to meaningfully adjust for confounding factors in our analyses. Second, all data regarding mothers' food choices and feeding styles were based on self-report and is subject to social desirability bias as well as participants' ability to accurately recall their children's food intake. Additionally, the feeding assessments used in this study (toddler diet questionnaire and the IFSQ) have not been validated in mothers with eating disorders, and these assessments may not capture more subtle restrictive feeding practices such as the special feeding approaches reported more frequently by mothers with histories of eating disorders. Third, the range of child ages (6-36 months) in this study was fairly broad. We recruited mothers such that the groups were similar for child age within 6-month age bands, so the mean child age between groups was not significantly different. However, the largest age group recruited was age 6-12 months - a time period when most children are just becoming accustomed to solid foods. While all the children in this study had been introduced to solid foods, 22 out of 50 mothers were still breastfeeding to some extent. Thus, these mothers' feeding practices were likely just being established and could change significantly after the children are weaned. Due to our small sample size, we were unable to conduct a subgroup analysis and evaluate differences in feeding measures across age groups. Fourth, this was a nonrandomised cohort study with comparison groups defined by eating disorder history. Differences between maternal groups could plausibly be due to some unknown and unmeasured characteristic related to both eating disorder history and an outcome variable. Finally, the sample was largely white and educated, so findings may not be generalisable to all mothers with histories of eating disorders.

Overall, the results of this study present a unique pattern of feeding for mothers with histories of eating disorders that warrants further investigation. These mothers reported a highly responsive feeding style, with less restrictive feeding than controls, and were more likely to report taking a restrictive special approach to feeding their child such as limiting processed foods or feeding organic foods only. Coupled with the mothers' own increased concerns over eating and general anxiety, the findings of responsive feeding involving 'special approaches' argues that these mothers may be more invested in their children's feeding. Future studies will need to investigate 
whether this increased attention to child feeding results in better self-regulation of eating and healthier diets or more rigid dietary rules that are perceived by children as restrictive.

\section{Acknowledgements}

We would like to thank the mothers who gave their time to participate in this study.

\section{Source of funding}

This research was supported by the National Institutes of Health Grant F30MH087998 (PI: ERH) and the American Society for Nutrition Gerber Foundation Predoctoral Fellowship to ERH. EAH is supported by the Robert Wood Johnson Foundation Nurse Faculty Scholar Program.

\section{Conflicts of interest}

The authors declare that they have no conflicts of interest.

\section{Contributions}

All the authors were involved in designing the research. ERH conducted the research and performed the statistical analysis with guidance from RMH. ERH drafted the manuscript with critical and intellectual feedback provided by $\mathrm{CMB}, \mathrm{MEB}, \mathrm{RMH}$, EAH and DSW. All authors approved of the current version of this manuscript.

\section{References}

Agras S., Hammer L. \& McNicholas F. (1999) A prospective study of the influence of eating-disordered mothers on their children. The International Journal of Eating Disorders 25, 253-262.

Bardone-Cone A.M., Harney M.B., Maldonado C.R., Lawson M.A., Robinson D.P., Smith R. et al. (2010) Defining recovery from an eating disorder: conceptualization, validation, and examination of psychosocial functioning and psychiatric comorbidity. Behaviour Research and Therapy 48, 194-202.

Beck A.T., Epstein N., Brown G. \& Steer R.A. (1988) An inventory for measuring clinical anxiety: psychometric properties. Journal of Consulting and Clinical Psychology 56, 893-897.

Beck A.T., Steer R.A., Ball R. \& Ranieri W. (1996) Comparison of Beck Depression Inventories-IA and -II in psychiatric outpatients. Journal of Personality Assessment 67, 588-597.

Birch L.L. \& Fisher J.O. (2000) Mothers' child-feeding practices influence daughters' eating and weight. American Journal of Clinical Nutrition 71, 1054-1061.

Birch L.L., Fisher J.O., Grimm-Thomas K., Markey C.N., Sawyer R. \& Johnson S.L. (2001) Confirmatory factor analysis of the Child Feeding Questionnaire: a measure of parental attitudes, beliefs and practices about child feeding and obesity proneness. Appetite 36, 201-210.

Blissett J. \& Farrow C. (2007) Predictors of maternal control of feeding at 1 and 2 years of age. International Journal of Obesity (2005) 31, 1520-1526.

Brinch M., Isager T. \& Tolstrup K. (1988) Anorexia nervosa and motherhood: reproduction pattern and mothering behavior of 50 women. Acta Psychiatrica Scandinavica 77, 611-617.

Britton J.R. (2011) Infant temperament and maternal anxiety and depressed mood in the early postpartum period. Women and Health 51, 55-71.

Bulik C.M., Sullivan P.F., Fear J.L., Pickering A., Dawn A. \& McCullin M. (1999) Fertility and reproduction in women with anorexia nervosa: a controlled study. Journal of Clinical Psychiatry 60, 130-135; quiz 135-137.

Cohen J. (1992) A power primer. Psychological Bulletin 112, 155-159.

Cooper Z. \& Fairburn C. (1987) The eating disorder examination - a semistructured interview for the assessment of the specific psychopathology of eating disorders. The International Journal of Eating Disorders 6, 1-8.

Dellava J.E., Hamer R.M., Kanodia A., Reyes-Rodriguez M.L. \& Bulik C.M. (2011) Diet and physical activity in women recovered from anorexia nervosa: a pilot study. The International Journal of Eating Disorders 44, 376382.

Duke R.E., Bryson S., Hammer L.D. \& Agras W.S. (2004) The relationship between parental factors at infancy and parent-reported control over children's eating at age 7 . Appetite 43, 247-252.

Fairburn C.G. \& Beglin S.J. (1994) Assessment of eating disorders: interview or self-report questionnaire? The International Journal of Eating Disorders 16, 363-370.

Fairburn C.G. \& Cooper Z. (1993) The eating disorder examination. In: Binge Eating: Nature, Assessment and Treatment (eds C.G. Fairburn \& G.T. Wilson), 12th edn, pp 317-360. Guilford Press: New York.

Faith M.S., Berkowitz R.I., Stallings V.A., Kerns J., Storey M. \& Stunkard A.J. (2004) Parental feeding attitudes 
and styles and child body mass index: prospective analysis of a gene-environment interaction. Pediatrics 114, e429-e436.

Farrow C.V. \& Blissett J.M. (2005) Is maternal psychopathology related to obesigenic feeding practices at 1 year? Obesity Research 13, 1999-2005.

First M.B., Spitzer R., Gibbon M. \& Williams J.B. (2002) Structured Clinical Interview for DSM-IV-TR Axis I Disorders, Research Version, Patient Edition. (SCID-I/P). Biometrics Research, New York State Psychiatric Institute, New York.

Fisher J.O. \& Birch L.L. (2002) Eating in the absence of hunger and overweight in girls from 5 to $7 \mathrm{y}$ of age. American Journal of Clinical Nutrition 76, 226-231.

Fisher J.O., Birch L.L., Smiciklas-Wright H. \& Picciano M.F. (2000) Breast-feeding through the first year predicts maternal control in feeding and subsequent toddler energy intakes. Journal of the American Dietetic Association 100, 641-646.

Gartner L.M., Morton J., Lawrence R.A., Naylor A.J., O'Hare D., Schanler R.J. et al. (2005) Breastfeeding and the use of human milk. Pediatrics 115, 496-506.

Honjo S. (1996) A mother's complaints of overeating by her 25-month-old daughter: a proposal of anorexia nervosa by proxy. The International Journal of Eating Disorders 20, 433-437.

Hudson J.I., Hiripi E., Pope H.G. Jr \& Kessler R.C. (2007) The prevalence and correlates of eating disorders in the National Comorbidity Survey Replication. Biological Psychiatry 61, 348-358.

Hurley K.M., Black M.M., Papas M.A. \& Caulfield L.E. (2008) Maternal symptoms of stress, depression, and anxiety are related to nonresponsive feeding styles in a statewide sample of WIC participants. Journal of Nutrition 138, 799-805.

Kuczmarski R.J., Ogden C.L., Grummer-Strawn L.M., Flegal K.M., Guo S.S., Wei R. et al. (2000) CDC growth charts: United States. Advance Data 314, 1-27.

Luce K.H. \& Crowther J.H. (1999) The reliability of the Eating Disorder Examination-Self-Report Questionnaire Version (EDE-Q). The International Journal of Eating Disorders 25, 349-351.

Mazzeo S., Slof-Op’t Landt M., van Furth E. \& Bulik C. (2006) Genetics of eating disorders. Annual Review of Eating Disorders Part 2, 17-34.

Mazzeo S.E., Zucker N.L., Gerke C.K., Mitchell K.S. \& Bulik C.M. (2005) Parenting concerns of women with histories of eating disorders. The International Journal of Eating Disorders 37 (Suppl.) S77-S79; discussion S87-79.

Micali N., Simonoff E. \& Treasure J. (2009) Infant feeding and weight in the first year of life in babies of women with eating disorders. Journal of Pediatrics 154, 55-60.e51.

Mond J.M., Hay P.J., Rodgers B., Owen C. \& Beumont P.J. (2004) Validity of the Eating Disorder Examination Questionnaire (EDE-Q) in screening for eating disorders in community samples. Behaviour Research and Therapy 42, 551-567.

Reba-Harrelson L., Von Holle A., Hamer R.M., Torgersen L., Reichborn-Kjennerud T. \& Bulik C.M. (2010) Patterns of maternal feeding and child eating associated with eating disorders in the Norwegian Mother and Child Cohort Study (MoBa). Eating Behaviors 11, 54-61.

Stein A., Woolley H., Cooper S.D. \& Fairburn C.G. (1994) An observational study of mothers with eating disorders and their infants. Journal of Child Psychology and Psychiatry and Allied Disciplines 35, 733-748.

Stein A., Murray L., Cooper P. \& Fairburn C.G. (1996) Infant growth in the context of maternal eating disorders and maternal depression: a comparative study. Psychological Medicine 26, 569-574.

Stein A., Woolley H., Cooper S., Winterbottom J., Fairburn C.G. \& Cortina-Borja M. (2006) Eating habits and attitudes among 10-year-old children of mothers with eating disorders: longitudinal study. The British Journal of Psychiatry: The Journal of Mental Science 189, 324-329.

Taveras E.M., Scanlon K.S., Birch L., Rifas-Shiman S.L., Rich-Edwards J.W. \& Gillman M.W. (2004) Association of breastfeeding with maternal control of infant feeding at age 1 year. Pediatrics 114, e577-e583.

Thompson A.L., Mendez M.A., Borja J.B., Adair L.S., Zimmer C.R. \& Bentley M.E. (2009) Development and validation of the Infant Feeding Style Questionnaire. Appetite 53, 210-221.

Toddler Diet Questionnaire (2007) Kansas Nutrition and WIC Services.

Wagner A., Barbarich-Marsteller N.C., Frank G.K., Bailer U.F., Wonderlich S.A., Crosby R.D. et al. (2006) Personality traits after recovery from eating disorders: do subtypes differ? The International Journal of Eating Disorders 39, 276-284.

Waugh E. \& Bulik C.M. (1999) Offspring of women with eating disorders. The International Journal of Eating Disorders 25, 123-133.

Wentz E., Gillberg I.C., Gillberg C. \& Rastam M. (2005) Fertility and history of sexual abuse at 10-year follow-up of adolescent-onset anorexia nervosa. The International Journal of Eating Disorders 37, 294-298.

Woodside D. \& Shekter-Wolfson L. (1990) Parenting by patients with anorexia nervosa and bulimia nervosa. The International Journal of Eating Disorders 9, 303-309. 